\title{
Application of Criterion-Meeting Assessment Method in Fundamentals of Nursing
}

\author{
Xueyan Chen, Jihong Wang*, Wenjuan Li \\ Nursing College, Beihua University Jilin City \\ Email: *jlwjh@sohu.com, hlxyhlxy05@sina.com
}

Received June 2013

\begin{abstract}
To investigate the results of criterion-meeting assessment method used for the operation test in fundamentals of nursing, 101 nursing undergraduates who entered Nursing College, Beihua Univercity in 2007, were randomly divided into experimental group and control group. The students in the control group were examined with the traditional assessment method, namely, the points were given the students one-time and estimated in a way of quantitative analysis. The students in the experimental group were examined with criterion-meeting assessment methods. The average score of students in the experimental group was higher than that in the control group $(\mathrm{P}<0.001)$, the difference was statistically significant, and $100 \%$ students in the experimental group got 90 - 100 points of the assessment standards. Our studies suggest that the method is not only conducive to fully mobilizing the enthusiasm of the students and students' establishing critical thinking, but also gives help to improve the overall quality of teachers. It can strengthen the experimental teaching, improve teachers' and students' senses of responsibility in teaching and learning and contribute to the good teaching result.
\end{abstract}

Keywords: Criterion-Meeting Assessment Method; Nursing

\section{Introduction}

Fundamentals of Nursing is an important basic course for students majoring in nursing and provides necessary knowledge and skills for nursing specialties in clinic [1]. The traditional operation test method focuses on proficiency in the operation, but ignores the evaluation of the importance of human care, the feelings of patients and the other aspects [2]. On the other hand, the method may show a contingency caused by the environment, emotion and live performance, and a limitation of $\boldsymbol{a}$ test for life during the process of the performance evaluation, which may have a direct impact on student learning initiative. In order to make the operation test more scientific, valid and reliable, a criterion-meeting assessment method has been implemented in our college and hereafter attached the follows.

\section{Subjects and Methods}

\subsection{Subjects}

101 nursing undergraduates who entered Nursing College, Beihua Univercity in 2007 were chosen as the subjects. All the students were female. They were randomly divided into experimental group (51) and control group

*Corresponding author.
(50). There was no significant difference in age or gender of students between the two groups $(\mathrm{P}>0.05)$ and they were comparable.

\subsection{Methods}

The assessment criterion of basic nursing skills edited by our college was used in the examination. The examination performance was randomly chosen from 15 items of performances which were commonly used and could show students' comprehensive abilities by the students. The students in the control group were examined with the traditional assessment method, namely, the points were given the students one-time and estimated in a way of quantitative analysis, the score less than 60 points was considered as a failure, the student who was in failure could have only one chance to make up and the make-up test result was recorded as 60 points, and he would be asked to be restudy this course fundamentals of nursing if a student could still not pass the make-up test. The students in the experimental group were examined with criterion-meeting assessment methods. There were three assessments, namely, the students who got $90-100$ standard points during the first assessment were awarded for the excellent and their final scores were $90-100$ points. The students who got $90-100$ standard points 
during the second assessment were awarded for the good and their final scores were 80 - 89. The students who got 90 - 100 standard points during the third assessment were awarded the pass and their final scores were 70 - 79 points. Those who could not reach the standard during the three assessments awarded for the failure and were required to restudy the course fundamentals of nursing.

In order to ensure the fairness of the assessment and avoid some subjective and objective factors to affect the results, some preparations for the assessment were implemented before the test.

\subsubsection{Establishing the Standards}

Nursing specialists who were in charge of clinical teaching and teachers who were responsible for the teaching of fundamentals of nursing were asked to screen the performances. 15 items of performances which were commonly used in clinic were prepared. The performances were presented in a way of synthetical cases and were required to reflect students' thinking and performance abilities. They jointly studied and discussed the preparation of the uniform assessment standards

\subsubsection{Strengthening the Practice}

In our college, an open system was implemented in the laboratories of basic nursing skills. The laboratories were open to students for three hours every evening and were managed by the students themselves. Some skilled teachers were asked to be on duty to instruct the students to manage the laboratories and finish experimental practice.

\subsubsection{Ensuring the Fairness of the Test}

During the assessments, the test questions were drawn randomly by the students on the scene and the teachers were divided into different groups (there were 3 teachers in each group), which could be convenient to unify standard and ensure the fairness of the assessments. Moreover, students' abilities of critical thinking and interpersonal communication skills were emphasized during the assessments.

\section{Results}

\subsection{Comparison of Students' Scores between the Two Groups}

Students' scores in the experimental group were higher than those in the control group and the difference between them was significant statistically $(\mathrm{P}<0.001)$. The comparison of students' scores between the two groups is showed in Table 1.

\subsection{Assessment Scores of Students in the Experimental Group}

Assessment scores of students in the experimental group are showed in Table 2. The excellent rate in the experimental group was $16.0 \%$. However, $100 \%$ students in the experimental group got 90 - 100 points of the assessment standards.

\section{Discussion}

The function of a test should include assessment, feedback, forecasting and incentive. Attribution theory proposed by Carol Dweck, a famous psychologist, considers that the meaning of an examination depends on different objectives for this exam. Those who take the score as a goal consider that a test only a measure of their own ability, it will make it self-esteem threatened if they fail, and then, they must show some negative emotional reactions such as shame, anxiety and depression, even boredom or contempt for the continued efforts, and those who take learning as a goal think that an examination is an approach to acquire knowledge and skills, and develop their ability, a failure means that their current studies should still fail to finish and in a sense, it will provide an opportunity to acquire higher intelligence, and the effort for it is taken as a way to activate their ability. Criterionmeeting assessment method is a good interpretation of this theory, which can not only make the results of an examination a motive power, but also provides a spiritual support and an objective opportunity on students.

\subsection{To Apply Learner-Based Teaching and Mobilize the Learning Initiative of Students}

\subsubsection{Learning to Fishing Is Better than Being Given} Fish

Criterion-meeting assessment method enables students to recognize the operational assessment is a learning pro-

Table 1. Comparison of students' scores between the two groups with two assessment method (\%).

\begin{tabular}{cccccc}
\hline Groups & $\begin{array}{c}>90 \\
\text { points }\end{array}$ & $\begin{array}{c}>80 \\
\text { points }\end{array}$ & $\begin{array}{c}>70 \\
\text { points }\end{array}$ & $\begin{array}{c}>60 \\
\text { points }\end{array}$ & Mean $\pm \mathrm{s}$ \\
\hline $\begin{array}{c}\text { Experimental } \\
\text { group (51) } \\
\quad \text { Control }\end{array}$ & 8 & 36 & 7 & 0 & $85.67 \pm 7.65$ \\
group (50) & 6 & 20 & 21 & 3 & $74.96 \pm 6.03$ \\
\hline $\mathrm{P}<0.001$. & & & & & \\
\hline
\end{tabular}

Table 2. Assessment scores of students in the experimental group(n = 51).

\begin{tabular}{ccc}
\hline & number & percentage (\%) \\
\hline Excellent & 8 & 16.0 \\
Good & 36 & 70.0 \\
Pass & 7 & 14.0 \\
Failure & 0 & 0.0 \\
\hline
\end{tabular}


cess in which they can combine theory and practice, consolidate and improve their practical skills, as well as a training process for their qualities and abilities. Through the assessments, they can understand that a failure to an examination does not mean real lack of their personal knowledge and abilities, the result is variable, controllable and positively proportional to their efforts and abilities, and the failure may become an aggressive driving force which may help them meet the assessment criteria. Through the practice, the students also understand that the improvement in the basic skills will be closely related to their clinical internships and future employment, which can fully mobilizes the enthusiasm of the students in the practical exercise and change them from passive learning to active learning [3].

\subsubsection{To Strengthen the Feedback Function of Examination}

During the application of Criterion-meeting assessment method, both teachers and students could timely get feedback information, which enables both teachers and students to recognize the deficiencies in teaching and learning. The method requires that the teachers should teach the students in a way closely integrated with clinic, namely, combining the assessment with specific cases. It also requires that the teachers should prepare adequately according to different cases and different training programs, and try to understand related comprehensive knowledge and proficient skills before the assessment so that they can better guide and assess the students [3], which should be conducive to the improvement in the overall quality of teachers.

During the assessment, the students' observation abilities, clinical thinking skills, and communication skills could be improved, which could promote them to pay more attention to human care and help to improve the overall quality of students.

Criterion-meeting assessment method also contributed to the improvement of the active mental activity for both teachers and students in the improvement of students' skills, and an equal and harmonious atmosphere between the teachers and the students could be built, which may close teacher-student relationship.

\subsubsection{Problems to Be Solved}

There were some problems to be solved in the application of criterion-meeting assessment method. The teachers had to spend more time, energy and physical exertion, a few individual students with fluke mind hoped that they could draw a procedure which would be easy for them in the operation, which might disturb the fairness of the assessment.

Our studies suggest that the implementation of criterion-meeting assessment method in the operation test of fundamentals of nursing should be regarded as a good way to improve the overall quality of students. The method is not only conducive to fully mobilizing the enthusiasm of the students and students' establishing critical thinking, but also gives help to improve the overall quality of teachers. It can strengthen the experimental teaching, improve teachers' and students' senses of responsibility in teaching and learning and contribute to the good teaching result.

\section{REFERENCES}

[1] X. H. Li, "Fundamentals of Nursing,” People’s Medical Publishing House, Beijing, 2006, pp. 1-2.

[2] Z. X. Zhou, J. H. Bian, Q. Wang et al., "Discussion on the Implementation Of Practice Examination Rating Certificate in Fundamentals of Nursing," Journal of Nurses Training, Vol. 23, No. 7, 2008, pp. 613-614.

[3] Y. Sheng, Y. Zhao and X. Zhang, "The Practice Of Method of Learning in Groups in the Nursing Skills Teaching," Chinese Journal of Nursing, Vol. 39, No. 7, 2004, pp. 531-53. 